
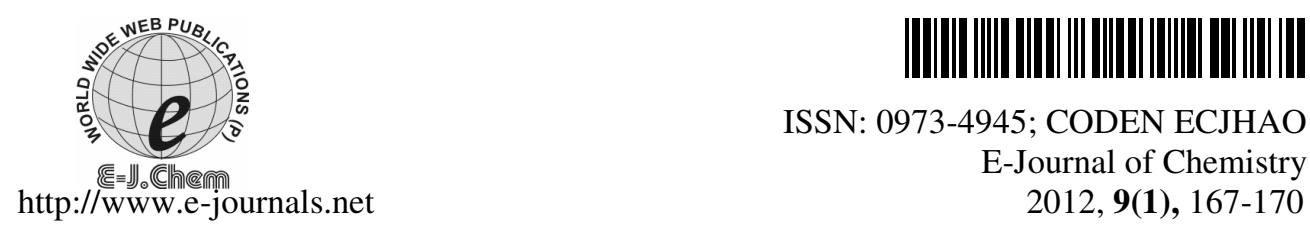

ISSN: 0973-4945; CODEN ECJHAO

E-Journal of Chemistry 2012, 9(1), 167-170

\title{
An Efficient and Inexpensive Synthesis of 2-Substituted Benzimidazoles in Water Using Boric Acid at Room Temperature
}

\author{
ZAHED KARIMI-JABERI and MOHAMMAD AMIRI \\ Department of Chemistry, Firoozabad Branch \\ Islamic Azad University, Firoozabad, Fars, Iran \\ zahed.karimi@yahoo.com
}

Received 13 June 2011; Accepted 13 August 2011

\begin{abstract}
Substituted benzimidazoles have been synthesized in a one-pot reaction from $o$-phenylenediamine and aldehydes in the presence of boric acid in water at room temperature. The method was proved to be eco-friendly, convenient and the products were isolated with good yields.
\end{abstract}

Keywords: Benzimidazoles, Boric acid, $o$-Phenylenediamine, Inexpensive synthesis

\section{Introduction}

The preparation of benzimidazoles has gained considerable attention in recent years. The benzimidazole is found in a variety of naturally occurring compounds and is of significant importance in medicinal chemistry. Their diverse applications include as potential antitumor agents $^{1}$, antimicrobial agents ${ }^{2}$, angiotensin II inhibitors ${ }^{3}$, inhibitors of HCMV replication ${ }^{4}$, selective neuropeptide YY1 receptor antagonists ${ }^{5}$. In addition, benzimidazoles are very important intermediates in organic reactions ${ }^{6}$.

Several methods have been reported for the synthesis of benzimidazoles ${ }^{7}$. The traditional synthesis of benzimidazole involves the reaction between $o$-phenylenediamine and a carboxylic acid or their derivatives at elevated temperature in the presence of strong acids such as polyphosphoric $\operatorname{acid}^{8}$ or mineral acids ${ }^{9}$ and thermal or acid promoted cyclization of $N$-( $N$-arylbenzimidoyl)-1,4-benzoquinoneimines ${ }^{10}$. Recently direct condensation of $o$-aryldiamines and aldehydes is the most convenient method for the preparation of these compounds. In this context some methods and catalysts have been reported such as indium triflate $^{11}$, iodine ${ }^{12}$, cetylpyridinium bromide ${ }^{13}$, PEG $400^{14}$, (bromodimethyl)sulfonium bromide $^{15}$ and ammonium acetate ${ }^{16}$. Although, these approaches are satisfactory for synthesis of benzimidazoles, the harsh reaction conditions, expensive reagents, use of toxic organic solvents and long reaction times limit the use of these methods. 
In recent years, water-mediated organic synthesis without using organic solvents has become one of the most important aspects in organic chemistry in order to meet the environmental demands. Carrying out organic synthesis in aqueous phase is highly challenging both from the synthetic view point and also from the impact of the environmental pollution ${ }^{17}$.

During the course of our systematic studies directed towards the development of environmentally friendly procedures for several important organic transformations ${ }^{18-20}$, we now describe a simple, general and efficient protocol for the synthesis of 2-substituted benzimidazoles using boric acid in water at room temperature (Scheme 1).

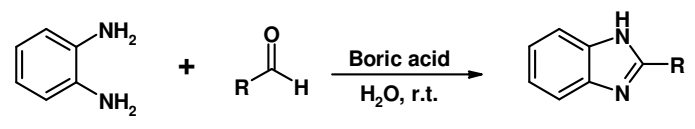

\section{Scheme 1}

Boric acid $\left(\mathrm{H}_{3} \mathrm{BO}_{3}\right)$ is a useful and environmentally benign catalyst which has been successfully utilized in numerous reactions, for example, the aza Michael addition ${ }^{21}$, Biginelli reaction ${ }^{22}$ transesterification of ethyl acetoacetate $^{23}$, mannich reaction ${ }^{24}$ and synthesis of $\alpha$-aminophosphonates and dibenzoxanthenes by our group ${ }^{25-26}$. It offers milder conditions relative to common mineral acids. Boric acid is a readily available and inexpensive reagent and can conveniently be handled and removed from the reaction mixture. Thus, the remarkable catalytic activities together with its operational simplicity make it the most suitable catalyst for the reaction of diamines with aldehydes.

\section{Experimental}

A mixture of aldehyde $(2 \mathrm{mmol}), o$-phenylenediamine $(2 \mathrm{mmol})$, boric acid $(0.1 \mathrm{~g})$ and water $(1 \mathrm{~mL})$ was stirred at room temperature for the appropriate time indicated in Table 1 . The progress of reactions was monitored by TLC (ethyl acetate/petroleum ether=1/4). After completion of the reaction, water $(5 \mathrm{~mL})$ was added and the mixture was stirred for $10 \mathrm{~min}$. The obtained solid was collected by filtration and purified by recrystallization from ethanol. Spectral data for selected products: Entry 4: mp 291-293 ${ }^{\circ} \mathrm{C} ;{ }^{1} \mathrm{HNMR}$ (250 MHz, DMSO-d6): $\delta 12.98(1 \mathrm{H}$, br s), 8.17, (2H, d, J = 8.5 Hz), 7.53-7.63 (4H, m), 7.19-7.21 (2H, m).

\section{Results and Discussion}

To optimize the reaction conditions, the reaction of $o$-phenylenediamine with benzaldehyde was used as a model reaction. Reactions at different conditions in the presence of boric acid revealed that the best conditions were using water as solvent at room temperature. After completion of the reaction, the catalyst (boric acid) can easily be separated from the reaction mixture by washing the product with water.

To show the generality of this method the optimized system was used for the synthesis of other derivatives. Several examples illustrating this novel and general method for the synthesis of dibenzoxanthenes are summarized in Table 1.

These data clearly show that different aromatic aldehydes were successfully converted into the corresponding benzimidazoles in high yields at room temperature. The presence of electron-withdrawing or electron-donating substituents on the aromatic ring makes no difference to the course of the reaction. Various functionalities present in the aryl aldehydes, such as halogen, methoxy and nitro groups were tolerated (Table 1). Furthermore, unsaturated aldehydes, such as cinnamaldehydes (Entry 9), gave the corresponding benzimidazoles without any polymerization or conjugate addition to the $\alpha, \beta$-unsaturated carbonyl group under the above reaction conditions. Moreover, heteroaromatic (Entries 10-12) 
were effective substrates to successfully execute couplings by boric acid. All products are known compounds and structures of them were confirmed by comparison with their known physical and spectral (NMR and IR) data ${ }^{11-16}$.

Table 1. Synthesis of 2-substituted benzimidazoles in the presence of boric acid

\begin{tabular}{|c|c|c|c|c|}
\hline Entry & Aldehyde & Product & $\begin{array}{c}\text { Time } \\
\text { min }\end{array}$ & $\begin{array}{c}\text { Yield, } \\
\%^{\mathrm{a}}\end{array}$ \\
\hline 1 & & & 30 & 92 \\
\hline 2 & & & 15 & 90 \\
\hline 3 & & & 20 & 91 \\
\hline 4 & & & 15 & 93 \\
\hline 5 & & & 15 & 90 \\
\hline 6 & & & 15 & 92 \\
\hline 7 & & & 30 & 84 \\
\hline 8 & & & 15 & 92 \\
\hline 9 & & & 20 & 95 \\
\hline 10 & & & 35 & 70 \\
\hline 11 & & & 15 & 70 \\
\hline 12 & & & 30 & 93 \\
\hline 13 & & & 25 & 75 \\
\hline 14 & & & 15 & $98^{\mathrm{b}}$ \\
\hline
\end{tabular}

${ }^{a}$ Isolated yield, ${ }^{b}$ conditions: o-phenylenediamine $(2 \mathrm{mmol})$ terphthaldehyde (1 $\left.\mathrm{mmol}\right)$ 


\section{Conclusion}

In conclusion this paper describes a convenient and efficient process for the synthesis of 2 -substitued benzimidazoles by one-pot reaction of $o$-phenylenediamine with aldehydes in the presence of boric acid in water. This method offers some advantages in terms of simplicity of performance, using water as solvent, low reaction times, low cost and it follows along the line of green chemistry. The catalyst is readily available and inexpensive and can conveniently be handled and removed from the reaction mixture. We believe that this procedure is convenient, economic and a user-friendly process for the synthesis of substituted imidazoles of biological and medicinal importance.

\section{References}

1. Denny W A, Rewcastle G W and Baguley B C, J Med Chem., 1990, 33(2), 814-819.

2. Fonseca T, Gigante B and Gilchrist T L, Tetrahedron, 2001, 57, 1793-1799.

3. Kohara Y, Kubo K, Imamiya E, Wada T, Inada Y and Naka T, J Med Chem., 1996, 39, 5228-5235.

4. Porcari A R, Devivar R V, Kucera L S, Drach J C and Townsend L B, J Med Chem., 1998, 41(8), 1252-1262.

5. Zarrinmayeh H, Zimmerman D M, Cantrell B E, Schober D A and Bruns R F, Bioorg Med Chem Lett., 1999, 9(5), 647-652.

6. Hasegawa E, Yoneoka A, Suzuki K. Kato T, Kitazume T and Yangi K, Tetrahedron, 1999, 55, 12957-12968.

7. Katritzky A R and Boulton A J, Advances in Heterocyclic Chemistry; Vol. 27; Academic: New York, 1980, 27, 241.

8. Preston P N, Weissberger A and Taylor E C, Chemistry of Heterocyclic Compounds; Part 1, Wiley: New York, 1981, 40, 6-60.

9. Kartritzky A R and Rees C W, Comprehensive Heterocyclic Chemistry; Pergamon: Oxford, 1984, 5, 457-474.

10. Benincori T and Sannicolo F, J Heterocycl Chem., 1988, 25, 1029-1033.

11. Trivedi R, De S K and Gibbs R A, J Mol Cat A Chem., 2006, 245, 8-11.

12. Gogoi P and Konwar D, Tetrahedron Lett., 2006, 47(1), 79-82.

13. Chakrabarty M, Karmakar S, Mukherjee R, Arima S and Harigaya Y, Monatsh Chem., 2009, 140, 375-380.

14. Mukhopadhyay C and Tapaswi P K, Tetrahedron Lett., 2008, 49, 6237-6240.

15. Das B, Holla H and Srinivas Y, Tetrahedron Lett., 2007, 48, 61-64.

16. Sharghi H, Asemani O and Khalifeh R, Synth Commun., 2008, 38, 1128-1136.

17. Lindstrom U M, Organic Reactions in Water; Blackwell Publishing: Oxford, 2007.

18. Karimi-Jaberi Z and Arjmandi R, Monatsh Chem., 2011, 142, 631-635.

19. Karimi-Jaberi Z, Amiri M and Sadeghi N, Synth Commun., 2010, 40, 2948-2953.

20. Karimi-Jaberi Z, Abbasi S Z, Pooladian B and Jokar M, E-J Chem., 2011, 8(4), 1895-1899.

21. Chaudhuri M K, Hussain S, Kantam M L and Neelima B, Tetrahedron Lett., 2005, 46, 8329-8331.

22. Tu S, Fang F, Miao C, Jiang H, Feng Y, Shi D and Wang X, Tetrahedron Lett., 2003, 44, 6153-6155.

23. Kondaiah G C M, Reddy L A, Babu K S, Gurav V M, Huge K G, Bandichhor R, Reddy P P, Bhattacharya A and Anand R V, Tetrahedron Lett., 2008, 49, 106-109.

24. Mukhopadhyay C, Datta A and Butcher R J, Tetrahedron Lett., 2009, 50, 4246-4250.

25. Karimi-Jaberi Z and Amiri M, Hetroatom Chem., 2010, 21, 96-98.

26. Karimi-Jaberi Z and Keshavarzi M, Chin Chem Lett., 2010, 21, 547-549. 


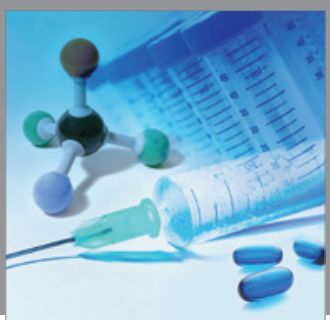

International Journal of

Medicinal Chemistry

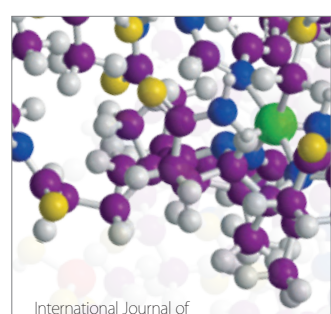

Carbohydrate Chemistry

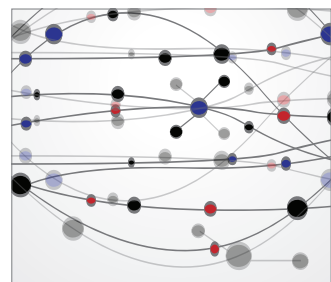

The Scientific World Journal
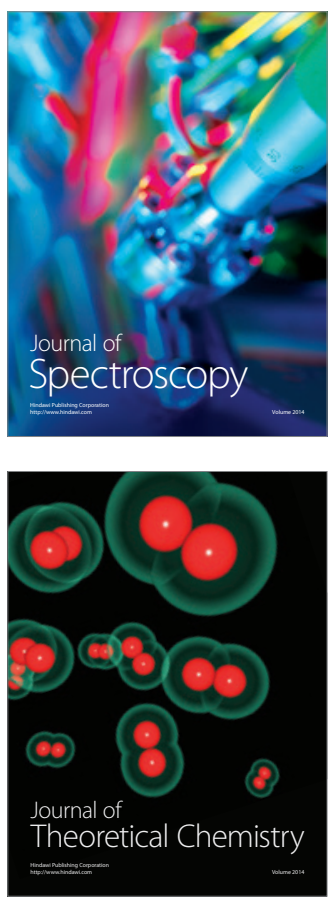
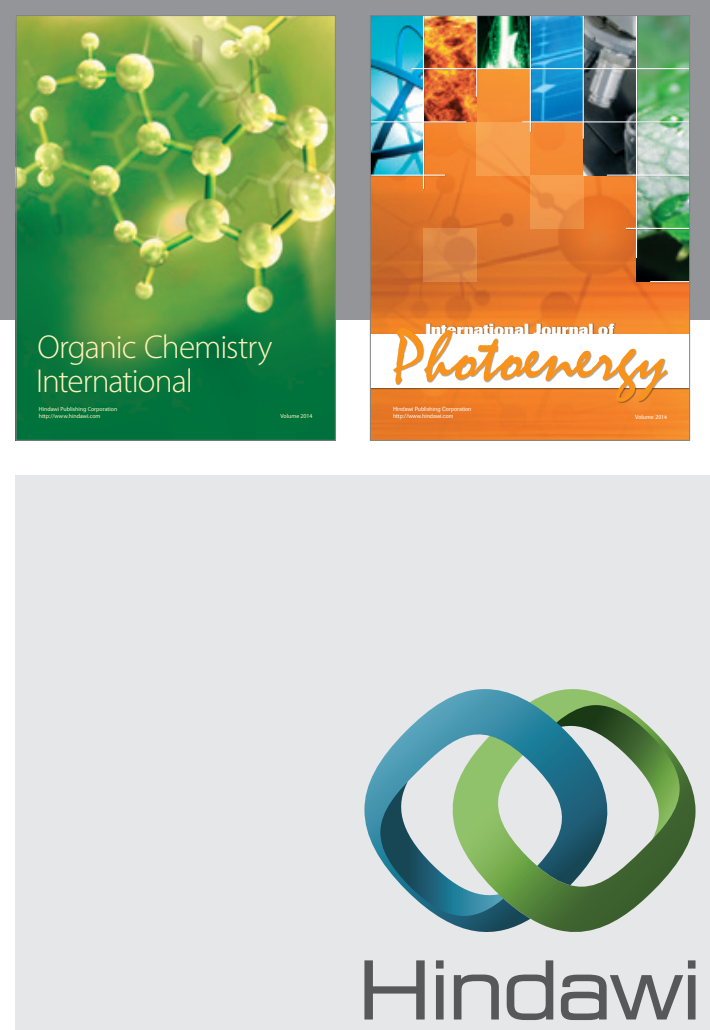

Submit your manuscripts at

http://www.hindawi.com
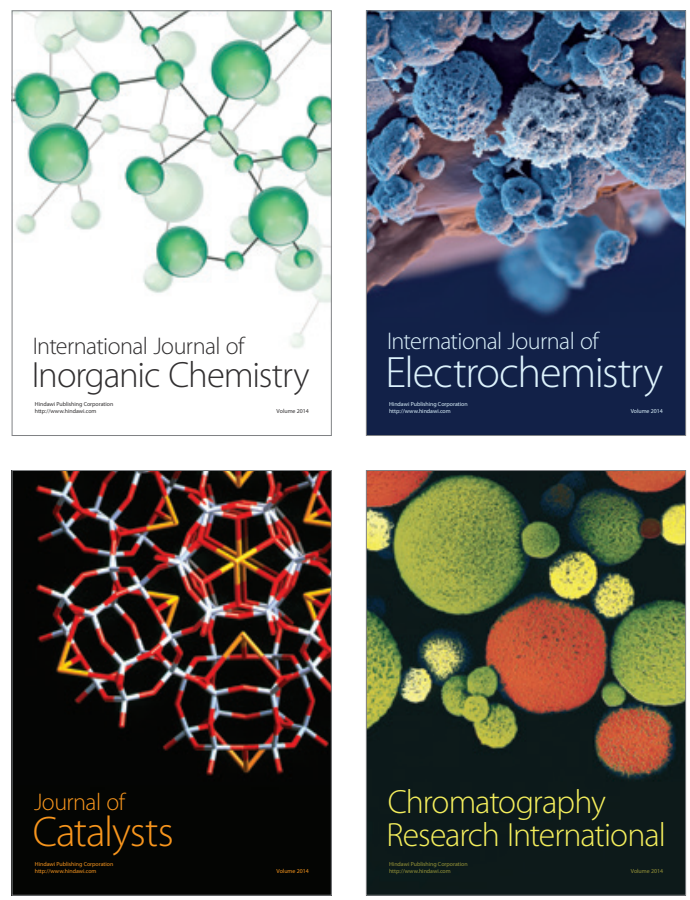
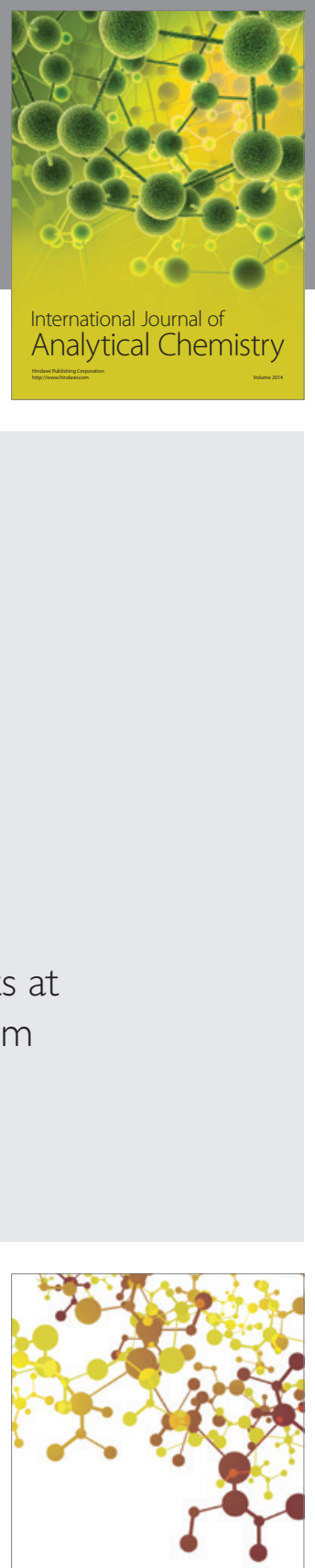

Journal of

Applied Chemistry
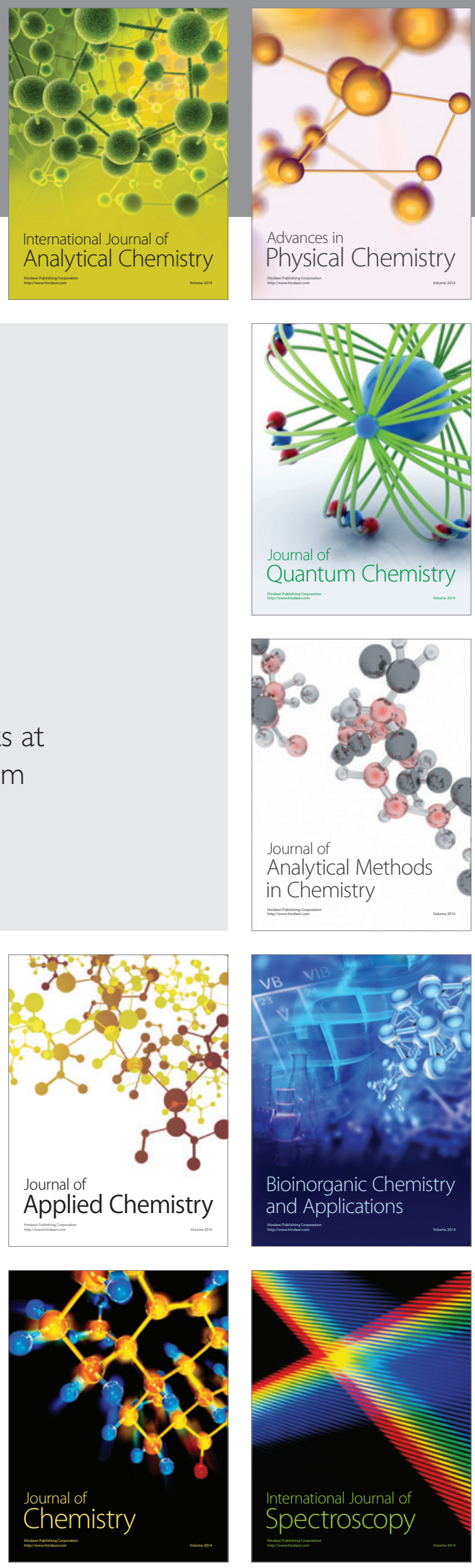